\title{
Studies of avoidable factors influencing death: a call for explicit criteria
}

\author{
Ragnar Westerling
}

\begin{abstract}
Objective - To analyse studies evaluating cases of potentially "avoidable" death.

Design - The definitions, sources of information, and methods were reviewed with a structured protocol. The different types of avoidable factors, - that is, deficiences in medical care that may have contributed to death -were categorised. The presence of explicit classifications and standards was examined. Basic criteria for quality of the studies were defined and the numbers of studies fulfilling these criteria were assessed.

Setting and participants - 65 studies, published during 1988-93 in peer reviewed medical journals for which the title, or abstract, or both indicated that they had analysed potentially avoidable factors influencing death. Studies analysing aggregated data only, were not included.

Results - Only one third of the studies fulfilled basic quality criteria, - namely, that the avoidable factors examined should be defined and the sources of information and people responsible for the judgements presented. The definitions used comprised two levels, one stating that there had been errors in management (process) and the other that the errors may have contributed to the deaths (outcome). Only $15 \%$ of the studies explicitly defined what type of factors they had looked for and $8 \%$ referred to specified standards of care.

Conclusions - Studies of avoidable factors influencing death may have considerable potential as part of a system of improving medical care and reducing avoidable mortality. At present, however, the results from different studies are not comparable, due to differences in materials and methods. There is a need to improve the quality of the studies and to define standardised explicit definitions and classifications.

(Quality in Health Care 1996;5:159-165)
\end{abstract}

Keywords: medical audit, malpractice, avoidable mortality, cause of death

Department of Social Medicine, Uppsala University, Akademiska sjukhuset, S-751 85 Uppsala, Sweden

Ragnar Westerling, senior lecturer identifying factors that may have contributed to the deaths. By pointing out precisely what may have gone wrong, these studies suggested the action needed to avoid a repetition of the error. ${ }^{1}$

The concept of studying avoidable mortality arose from this tradition. ${ }^{2-6}$ Certain causes of death, for which there is knowledge about therapeutic or preventive measures, have been defined as avoidable death indicators. ${ }^{2-4}$ During the 1980 s and 1990s several studies on avoidable mortality have been published. ${ }^{56}$ These have mainly included studies of differences in avoidable death rates between different health administrative areas and countries (both showing considerable regional variation), and over time. ${ }^{5} \mathrm{~A}$ high avoidable death rate is a warning signal motivating in depth studies of the chain of events and quality of care preceding the potentially avoidable death. ${ }^{2-4}$ There are, however, very few studies of this kind directly connected to the avoidable mortality studies.

Medical audits that have identified avoidable factors influencing death - that is, deficiencies in medical care that may have contributed to death - have attracted considerable attention. ${ }^{78}$ In the United Kingdom, the House of Commons Committee of Public Accounts has recommended that the Department of Health encourages managers and clinicians to investigate avoidable deaths and remedy any deficiencies. $^{7}$

In this paper recently published studies of avoidable factors influencing death are reviewed and analysed. The aim is to illustrate some of the methodological issues related to studies of this kind and to contribute to methodological development.

\section{Material and methods}

PAPERS INCLUDED IN THE STUDY

A Medline search of peer reviewed medical journals was performed exploring the keywords "mortality" and "cause of death". Mortality was included both as a keyword and as a subheading. The keywords were combined in the search together with the text words "avoidable" or "preventable" included in the title or abstract of the studies. In a second search the keyword "medical audit" was used combined with the keyword mortality or cause of death. The files included studies from 1988 to 1993 . The search was performed with the support of a trained librarian.

Studies reviewing deaths and stating that there were avoidable factors influencing death or that deaths could have been prevented or that between $40 \%$ and $60 \%$ of deaths in these areas were preventable. Attention was paid to 
avoided (inclusion criteria) were identified from the abstracts. Papers analysing aggregated data only were excluded. The study was limited to papers published in English.

In the first search 401 papers were found that used the text words avoidable or preventable in the abstract or title of the manuscript together with the keywords mortality or cause of death. Sixty two of these (15\%) met the inclusion criteria of this study. In the second search 188 papers were indexed by the keyword medical audit together with the keywords mortality or cause of death. Fifteen of these studies $(8 \%)$ met the inclusion criteria of this study. Thirteen of these had already been detected by the first text word based search. Thus two further studies were included by the second search.

In a third step the references of these 64 articles were checked. One further paper meeting the criteria was found in the manual search and this paper was also included. Thus, in total 65 papers were analysed. ${ }^{9-73}$

Figure 1 shows the proportions of the 65 papers detected by the different search strategies; $95 \%$ of the papers were found in the first text word based search.

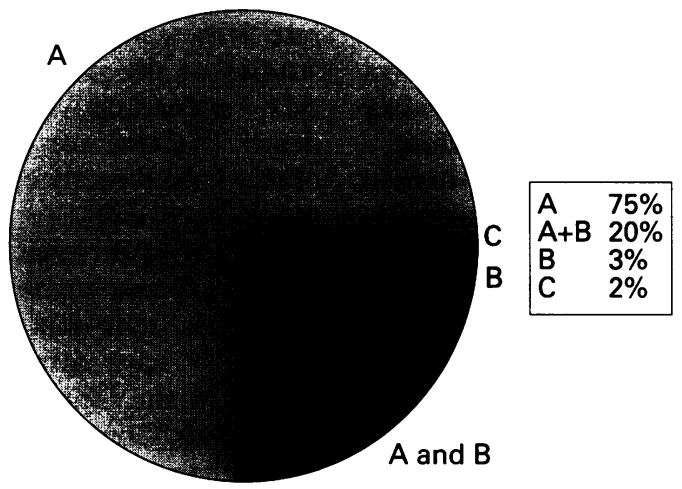

Figure 1 The proportion of the 65 papers detected by the different search strategies. $(A)$ Papers detected only by the text words avoidable or preventable (together with the keywords mortality or cause of death, Medline search). ( $A$ and $B)$ Papers detected both by the text words avoidable or preventable and the keyword medical audit (together with the keywords mortality or cause of death; Medline search). (B) Papers detected only by the keyword medical audit (together with the keywords mortality or cause of death; Medline search). (C) Paper found in the reference lists of the other papers.

Seventy five per cent of the studies would not have been found if only keyword based searches had been performed.

ANALYSIS OF THE PAPERS

The 65 studies were analysed with a structured protocol (box). The questions are based on the concept of quality of care. Such studies often refer to the theoretical work of Donabedian, who thought that quality of care deals with the optimal application of medical science and technology to benefit health. ${ }^{74}$ One of the fields of concern in this review is how the avoidable factors were defined and how this definition relates to the concept of quality of care.

The quality of care should be related to different components of health care: the structure, process, and outcome of care. ${ }^{75}$ Donabedian has also discussed the study of
Questions asked in structured protocol for review of studies of avoidable factors influencing death

- What conditions were studied?

- How many deaths were included?

- What definition of avoidable factors was used?

- Did they use any explicit criteria for what type of factors they studied?

- Did they define any standard of care?

- What sources of information were used?

- Who was responsible for the judgements?

- What kind of avoidable factors did they find?

- For what proportion of deaths did they find avoidable factors?

- Did they analyse the reasons for the deficiences in care?

preventability in adverse outcomes.According to his ideas, the mere finding of the occurrence of an adverse event almost always leads to questions about the contribution of the quality of care to the outcome. ${ }^{1}$ If there has been a failure it is not always known how the failure has occurred. It is, therefore, also important to study, case by case, the process of care preceding the adverse events.

When assessing the studies of avoidable factors influencing death it is important to find out whether they analysed avoidable factors related to the process of care and whether they made judgements about the influence of care on the outcome - that is, the deaths. The definitions of avoidable factors in the papers were therefore classified according to this concept.

Different criteria can be defined for quality assessment. ${ }^{76}$ The term criteria denotes certain aspects of the structure, work, or result of health care affecting its quality. The assessment of quality of care may be based on explicit criteria defined in advance or on implicit judgements. ${ }^{77}$ In this study I assessed whether the papers explicitly had defined what types of avoidable factors (aspects of care preceding death) they would study.

Different types of avoidable factors found were categorised into those concerned with the prevention, diagnosis, treatment, and complications of disease as well as those connected to organisation of health care and factors related to the patient.

Also, I analysed whether the papers referred to any standard of care in their assessment. Standards are the formal statements of how different medical conditions should be managed - that is, what quality of care that patients should expect. ${ }^{76-78}$ Defined standards could be the basis for medical audits striving to identify potential deficiences in care. They may thus be of potential importance for studies of avoidable factors influencing death.

To choose strategies for improving the quality of care information on why the deficiences in care occurred is important. ${ }^{78}$ Attention was therefore also paid to whether the studies had analysed the reasons for the deficiences.

The scope for evaluating the different aspects of care may depend on what information is available. ${ }^{78}$ The reliability of the assessment may also be influenced by the number of people responsible for the judgements - for instance, if a panel of assess- 
ers was used and whether members of the staff responsible for the care of the patient participated in the judgements. ${ }^{78}$ This review documents both the sources of information used in the papers and who was responsible for the judgements.

The criteria for the basic level of quality of the studies were that avoidable factors were defined, that the sources of information were presented, and that the people responsible for judgements were specified. This information is necessary to understand the methods and the relevance of the paper.

\section{Results}

CONDITIONS STUDIED IN THE PAPERS

Table 1 shows the conditions included in the studies. Nearly half of the studies analysed death associated with trauma $(48 \%) .^{9-39}$ Some of these studies concentrated on elderly people $^{13}$ or on children. ${ }^{15-2131}$ Other studies dealt with the outcome of certain types of trauma, such as head injuries. ${ }^{18-2228}$ The next most common conditions were perinatal mortality $(20 \%)^{40-52}$ and maternal mortality $(11 \%) .^{53-59}$

The mean (range) number of deaths included in the studies was 227 (14-1362).

\section{DEFINITION OF AVOIDABLE FACTORS}

Half of the studies presented a definition of avoidable factors and the other half contained no such definition (table 2).

Forty four per cent of the studies included some judgements on the process of care in their definition. In $32 \%$ the actual care was compared with accepted standards when deciding whether fatalities could be considered preventable. In $8 \%$ of the studies the standards were specified. Standards were defined by referring to a certain committee, ${ }^{41}$ to standardised guidelines, ${ }^{25}$ or were explicitly defined in the paper..$^{24850}$ No references to research evidence were presented, however. Other authors wrote in more general terms about optimal care ${ }^{24}$ or accepted standards. ${ }^{4042} 4652$

Six per cent of the studies made judgements about the process of care without defining any connection with outcome. ${ }^{955358}$ Forty two per cent of the studies, however, concluded that the avoidable factors of care had influenced the outcome (deaths). Eleven per cent defined different levels of certainty concerning the judge-

Table 1 Conditions included in studies of avoidable factors influencing death under review

\begin{tabular}{lll}
\hline Condition & $\begin{array}{l}\text { Studies } \\
n\end{array}$ & $\begin{array}{l}\text { Deaths studied } \\
n \text { (mean) }\end{array}$ \\
\hline Trauma & 31 & $226^{\star}$ \\
Perinatal mortality & 13 & 290 \\
Maternal mortality & 7 & 150 \\
Asthma & 3 & 85 \\
Mixture of conditions in & 5 & 116 \\
$\quad$ certain departments or & & \\
$\quad$ populations & & 36 \\
Certain pediatric conditions & 2 & 39 \\
Diabetes & 2 & 80 \\
Perioperative deaths & 1 & 81 \\
Stroke and hypertensive & 1 & \\
$\quad$ disease & &
\end{tabular}

* Not specified in one of the studies; mean number of deaths calculated for 30 studies.
Table 2 Type of definition of avoidable factors in studies of avoidable factors influencing death

\begin{tabular}{lc}
\hline Type of definition & $\begin{array}{l}\text { Studies } \\
n(\%)\end{array}$ \\
\hline $\begin{array}{lc}\text { Process oriented } \\
\text { Outcome oriented definition }\end{array}$ & $4(6)$ \\
$\begin{array}{l}\text { Combined definition (process and } \\
\text { outcome) }\end{array}$ & $25(3)$ \\
No definition & $34(52)$ \\
\hline
\end{tabular}

* Errors in management or factors in care that were not optimal.

† Factors that influenced the death.

ment - for instance, that the deaths were possibly or definitely preventable. ${ }^{12142351596873}$

\section{ASSESSMENT OF AVOIDABLE FACTORS}

In $85 \%$ of the studies the sources of information were presented (table 3). Sixty three per cent used medical records as a basis for their judgements and in $18 \%$ this was the only material used. In $12 \%$ of the studies record data covering different stages of medical care were collected, including medical records from prehospital care. ${ }^{112223437455865}$

Thirty five per cent of the studies included necropsy reports and in one study this was the only material used. In three of the studies that did not include necropsy data the validity of the causes of death was evaluated by the research group. ${ }^{616272}$ In $17 \%$ of the studies a prospective database was established in the department to collect specified information. Other sources of information were questionnaires or structured interviews with doctors, other staff members and relatives $(14 \%),{ }^{45465159-626465}$ as well as police reports $(7 \%){ }^{15313238}$

Fifteen per cent of the studies presented some explicit classifications of the different types of avoidable factors that were assessed in their evaluations - for example, different components of medical care, such as prehospital, emergency department, and operating care. $^{12-72}$

In $65 \%$ of the studies a panel was responsible for the statements (table 4 ). The panel consisted of external experts $(20 \%)$, staff members of the departments $(5 \%)$, or combinations of both external and internal members $(8 \%)$. In $32 \%$ of the studies it was not further specified whether the panel consisted of external assessors, internal staff members, or both. In $12 \%$ of the studies the judgements were made by the authors themselves and in $31 \%$ no specific assessor was mentioned.

Table 3 Sources of information for studies of avoidable factors influencing death

\begin{tabular}{lc}
\hline Source of information & $\begin{array}{l}\text { Studies } \\
n(\%)\end{array}$ \\
\hline Medical records & $41(63)$ \\
Necropsy reports & $23(35)$ \\
Prospective database & $11(17)$ \\
Questionnaires to staff members & $5(8)$ \\
Interviews with relatives & $4(6)$ \\
Police reports & $4(6)$ \\
Death certificates & $4(6)$ \\
Questionnaires to relatives & $3(5)$ \\
Not presented & $10(15)$ \\
\hline
\end{tabular}


Table 4 The people responsible for judgements of avoidable factors influencing death

\begin{tabular}{lc}
\hline & Studies \\
Responsible people & $n(\%)$ \\
\hline Authors & $8(12)$ \\
External panel & $13(20)$ \\
Internal panel & $3(5)$ \\
Combined panel & $5(8)$ \\
Panel, external or internal not specified & $21(32)$ \\
Not specified & $20(31)$ \\
\hline
\end{tabular}

Table 5 Studies of avoidable factors fulfilling basic quality criteria*

\begin{tabular}{lc}
\hline Criteria fulfilled & $\begin{array}{l}\text { Studies } \\
n(\%)\end{array}$ \\
\hline 0 & $3(5)$ \\
1 & $11(17)$ \\
2 & $30(46)$ \\
3 & $21(32)$ \\
\hline ॠAvoidable factor was defined, sources of information were \\
presented, and the people responsible for judgements were \\
specified.
\end{tabular}

Table 5 shows that only 21 (32\%) of the studies reviewed fulfilled my basic quality criteria: they presented a definition of avoidable factors, the sources of information, and the people responsible for the judgements. Of these studies, however, 10 should have specified further whether the review panels were external or not.

\section{AVOIDABLE FACTORS IDENTIFIED}

Table 6 shows the types of avoidable factors reported. About half of the studies reported inadequate diagnosis and half of the studies inadequate treatment. A delay in treatment was reported in $31 \%$ and a delay in diagnosis in $22 \%$. Thirty four per cent of the studies reported errors in the management of complications of the diseases, such as lack of prevention, recognition, or treatment of complications. Twenty per cent reported that psychosocial factors or delay in seeking help had affected the patients, but only $5 \%$ of the studies reported lack of preventive measures. Seventeen per cent of the studies made remarks on the organisation of care, mainly poor cooperation between different levels of care.

The numbers and types of errors detected varied between the different conditions studied. For trauma deaths, the avoidable factors were mainly related to hospital care, such as delays in the diagnosis of injury, ${ }^{101118}$ unrecognised severity of diagnosis, ${ }^{30}$ or a lack of or delay in surgical treatment, ${ }^{12152627}$ as well as errors in the management of complications such as sepsis, aspiration, and pulmonary embolism. ${ }^{1520-22293238}$ In the studies of trauma death the mean (range) proportion of fatalities with avoidable factors was $27 \%(3 \%-65 \%)$.

For maternal mortality the mean (range) proportion of deaths with avoidable factors present was $76 \%(44 \%-100 \%)$. The results included factors in the organisation of health care, such as delay in transfer to central hospital; ${ }^{4655}{ }^{57}$ patient factors, ${ }^{5557} 58$ such as the late presentation for treatment; and hospital factors, ${ }^{559}$ such as failure or delay in diagnosis, surgery, or treatment.
Table 6 Types of avoidable factors reported by studies of avoidable factors influencing death

\begin{tabular}{ll}
\hline Type of factor & $\begin{array}{l}\text { Studies } \\
n(\%)\end{array}$ \\
\hline Lack of prevention & $3(5)$ \\
Delay in seeking help & $8(12)$ \\
Lack of health information & $1(2)$ \\
Bad compliance & $2(3)$ \\
Psychosocial factors & $7(11)$ \\
Delay of diagnosis & $14(22)$ \\
Inadequate diagnosis & $29(45)$ \\
Delay of treatment & $20(31)$ \\
Inadequate treatment & $33(51)$ \\
Lack of prevention of complications & $8(12)$ \\
Delayed recognition of complications & $9(14)$ \\
Inadequate treatment of complications & $11(17)$ \\
Bad cooperation between different levels of & $8(12)$ \\
care & \\
Care not available & $2(3)$ \\
Failure of follow up & $1(2)$ \\
Not specified & $7(11)$ \\
\hline
\end{tabular}

For perinatal mortality the mean (range) proportion of deaths in the presence of avoidable factors was $43 \%(21 \%-81 \%)$. Some factors were related to the mother, such as non-compliance, ${ }^{45}$ substance misuse, ${ }^{45}$ and late arrival. ${ }^{47}$ Other factors were due to inadequate medical care before, during, or after labour, mainly regarding the detection and treatment of complications, ${ }^{41-454748}$ such as increased blood pressure and toxaemia of the mother ${ }^{41}{ }^{47}$ and asphyxia ${ }^{4243}$ or infections of the baby. ${ }^{44}$

For asthma the mean (range) proportion of deaths with avoidable factors present was $49 \%$ $(39 \%-80 \%)$. Several studies reported a delay in seeking professional help, ${ }^{60-62}$ which was also found to be related to lack of information on the danger of grave clinical signs and lack of family education. ${ }^{60}$ Another factor was the presence of geographically isolated patients. ${ }^{6162}$ Other avoidable factors were inadequate assessment or treatment of asthma before final illness and inadequate treatment of the final episode. ${ }^{60-62}$

Only $5 \%$ of the studies analysed the reasons for the deficiences in care. ${ }^{185073}$ The reasons were mainly structural such as poor equipment ${ }^{73}$ and poor access to senior specialist opinions. ${ }^{18}$ Other studies described a chain of events in which one avoidable factor had led to another - for instance, diagnostic deficiences leading to therapeutic errors. ${ }^{48771}$

\section{Discussion}

AREAS FOR METHODOLOGICAL IMPROVEMENT The studies of avoidable factors influencing death have pointed out deficiencies in medical care and potential improvements. Some factors were related to the way in which medical services were organised. Most findings, however, gave information on areas for special attention of medical staff, mainly concerning diagnosis, treatment, and management of complications of the diseases.

This review, however, shows up several problems in the design of the studies. Only about one third fulfilled the basic criteria namely, a definition of the avoidable factors, and specificaton of the sources of information and the people responsible for the judgements. The methods used in the other studies varied. 
The review was limited to papers in peer reviewed medical journals in the period 198893, most of them indexed in Medline. The proportion of problems in quality found may be different in reports not selected for this study - for instance, in those not published in papers. The aim of this study is not, however, to make an overall statement about the quality of studies of this type but to show some of the problems in a sample of published studies. Although, the review included different conditions there are some common methodological issues. The results of this study imply a need for standardisation of definitions and methods.

Despite variations in wording, most of the definitions of avoidable factors combined judgements on the process and outcome of care. For instance, avoidable factors have been defined as deficiencies in the medical care (process) that may have contributed to death (outcome). This definition seems to be reasonable as the importance of analysing the connection between the process and outcome of care has been emphasised. ${ }^{75}$

The fruitfulness of the concept, however, depends on the evidence that medical intervention may affect the outcome. ${ }^{679}$ This is in accordance with the later development of the avoidable mortality method, which has been based on the general principle that each disease studied has explicitly defined effective interventions by the providers of health care. ${ }^{235}$

In this review only $16 \%$ of the studies presented explicit classifications of the different types of avoidable factors that they were looking for. Explicit criteria have several advantages. ${ }^{7780}$ The criteria can be standardised and their reasonableness can be discussed and verified. The evaluations will also be easier to perform. ${ }^{77}$

In the studies reviewed there were relatively few avoidable factors related to prevention, psychosocial conditions, and organisation of health care by comparison with those about diagnosis and treatment. As the types of factors were not explicitly defined we do not know whether this lack could be explained by the fact that the experts were not looking for factors of this kind, did not have information about them, or whether they were not considered to have any relevance to the avoidance of the deaths.

The review also showed that most of the studies did not refer to any defined standard of medical care. The development of clinical guidelines and standards of quality of care should be an area of concern for further studies. $^{7881} 82$

The sources of information varied between the studies. Medical records and necropsy reports were the materials most used. About $80 \%$ of studies used more than one source of information. This would be appropriate as reliability has been found to increase when more than one source is used ${ }^{12}$ and this technique may also give information on different components of care. For instance, prehospital records and questionnaires may give information on long term management ${ }^{78}$ and necropsy reports may give information on diagnostic errors and complications in the final stage of a disease. ${ }^{83-86}$ Few of the studies reviewed had, however, collected data from medical care outside the hospital. This may have limited the potential for detecting deficiencies in the long term management of patients. ${ }^{78}$

The completeness and quality of data have been found to be critical points in medical audit. $^{78}$ It thus seems reasonable to let the experts note whether insufficient information made it difficult to decide on the presence or absence of avoidable factors. ${ }^{1252}$ This procedure might provide incentive for improvements in routine recording of medical data.

FUTURE ROLE OF STUDIES OF AVOIDABLE FACTORS INFLUENCING DEATH

The importance of the different methodological remarks depends on the purpose of the studies. The concept of avoidable death has mainly been used in epidemiological studies of variation in avoidable mortality between different regional areas. ${ }^{3-5} 87$ A high death rate is a warning signal that should lead to further studies of the quality of care and the course of events preceding death. Avoidable mortality is an overall measure of the outcome of the healthcare system. ${ }^{68}$ Variation in death rates may be explained by differences in incidence or severity of disease and by differences in the cause of death classification between areas, as well as by random factors. ${ }^{89} 90$ Variation in death rates may also reflect differences in the frequency and type of avoidable factors influencing death.

Studies of avoidable factors may, thus, form a part of an analysis of how the differences in death rates can be explained. This is in accordance with Donabedian's view that measures of outcome (avoidable mortality) should be combined with measures of the process (avoidable factors) of care to validate whether the outcome reflects the quality of care. ${ }^{75}$ There are, however, few studies of this kind. One exception is the evaluation of the declining death rates for appendicitis among children under the age of 15 in England and Wales between the 1960s and the 1980s. Pledger et al compared the frequency of avoidable factors between the two decades. ${ }^{91}$ Many avoidable factors were eliminated in the 1980s compared with the 1960s. Among these were complications such as sepsis, hyperpyrexia, and convulsions, as well as shortcomings in anaesthesia. Other factors remained, such as difficulties in diagnosis and the resulting delay in starting treatment. To compare the results, standardisation of methods - such as the definition of explicit criteria and the use of external panels - is important. ${ }^{77} 7880$

Studies of avoidable factors influencing death may also potentially be part of the aim of an audit on improving the quality of care. For this purpose it is important that local clinics participate actively in the measures and feedback of the results. ${ }^{78}$ Furthermore, as pointed out by Crombie $e t a l$, it is also important to try to identify the reasons for the occurrence of the deficiencies, and not only their 
nature. ${ }^{78}$ Accordingly medical audits should include questions on the structure of care for instance, the way the delivery of health care is organised and the experience of the medical staff involved in care. ${ }^{7578}$ So far, however, the reasons for the deficiences have seldom been analysed in studies of avoidable factors preceding death.

Studies of avoidable factors influencing death may have considerable potential as part of a system of improving medical care and reducing avoidable mortality. As shown in this study, there is, however, a need to further improve and standardise the methods.

I thank Professor Claes-Göran Westrin and Professor Björn Smedby, Uppsala, for their comments and Olga Klauber, librarian at the University Hospital Medica Library at Uppsala University, for help with the search of papers.

1 Donabedian A. The study of preventability in adverse outcomes. In: Exploration in quality assessment and monitoring, vol 3: the methods and findings of quality assessment and ing, vol 3: the methods and findings of quality assessment and monitoring. An

2 Rutstein DD, Berenberger W, Chalmers TC, Child GC, Fischmen AP, Perrin EB. Measuring the quality of medical care. N Engl f Med 1976;294:582-8.

3 Holland WW, ed. European Community atlas of avoidable death. Oxford: Commission of the European Communities Health Services Medical Publications, 1988. (Research series No 3.)

4 Holland WW, ed. European Community atlas of avoidable death. 2nd ed. Vol 1. Oxford: Commission of the European Communities Health Services Medical Publications, 1991. (Research series No 6.)

5 Mackenbach JP, Bouvier-Colle MH, Jougla E. Avoidable mortality and health services: a review of aggregate data studies. F Epidemiol Community Health 1990;44:106-11.

6 Westerling R. The avoidable mortality method. Empirical studies using data from Sweden [thesis]. Uppsala: Department of Social Medicine, Uppsala University, 1993.

7 Wolfe C. Deaths from stroke in younger people. BMF 1993; 307:1020-1.

8 Yates DW. Action for accident victims. Plans to stop patients dying from major trauma. BMF 1988;297:1419-20.

9 Muckart DJJ, Thomson SR. Undetected injuries: a preventable cause of increased morbidity and mortality. Am $\mathcal{F}$ Surg 1991;162:457-60.

10 Phair IC, Barton DJ, Barnes MR, Allen MJ. Deaths following trauma: an audit of performance. Ann R Coll Surg Engl 1991;73:53-7.

11 Cayten CG, Stahl WM, Agarwal N, Murphy JG. Analyses of preventable deaths by mechanism of injury among 13500 trauma admissions. Ann Surg 1991;214:510-21.

12 MacKenzie EJ, Steinwachs DM, Bone LR, Floccare DJ, Ramzy AI. Inter-rater reliability of preventable death judgments. F Trauma 1992;33:292-303.

13 Pellicane JV, Byrne K, DeMaria EJ. Preventable complications and death from multiple organ failure among geriatric trauma victims. ₹ Trauma 1992;33:440-4.

14 Davies J W, et al. An analysis of errors causing morbidity and mortality in a trauma system. A guide for quality improvement. F Trauma 1992;32:660-6.

15 Wheathey J, Cass D T. Traumatic deaths in children: the importance of prevention. Med F Aust 1989;150:72-8.

16 Wilson DS, McElligott J, Fielding LP. Identification of preventable trauma deaths: confounded inquiries? I Trauma 1992;32:45-51.

17 Kubalak G, Rhodes M, Boorse D, D'Amelio LF. Unexpected death on the non-ICU trauma ward. $f$ Trauma 1991;31:1258-62

18 Phair IC, Barton DJ, Allen MJ, Barnes MR. Preventable deaths after head injury: a clinical audit of performance. Ann R Coll Surg Engl 1991;22:353-6.

19 Webb GL, McSwain NE, Webb WR, Fodriguez C. Emergency department deaths. Am $\mathcal{f}$ Surg 1990;159:377-

20 Davies JW, et al. The significance of critical care errors in causing preventable death in trauma patients in a traum system. F Trauma 1991;31:813-9.

21 Sharples PM, et al. Avoidable factors contributing to death of children with head injury BMF 1990;300:87-91.

22 Draaisma JM, deHaan AFJ, Goris RJA. Preventable trauma deaths in The Netherlands - a prospective multicenter study. F Trauma 1989;29:1552-7.

23 Pories SE, Gamelli RL, Pilcher DB, Vacek P, Jones J, Harris F, Goodwin G. Practical evaluation of trauma deaths. $\mathcal{f}$ Trauma 1989;29:1607-10.

24 Rivara FP, Maier RV, Mueller BA, Luna GA, Dicker BG, Herman CM, et al. Evaluation of potentially preventable
deaths among pedestrian and bicyclist fatalities. $\mathcal{\exists} A M A$ 1989;261:566-70.

25 Campbell S, Watkins G, Kreis D. Preventable deaths in self-designated trauma system. Am Surg 1989;55:478-80.
26 Anderson ID, Woodford $M$, deDombal FT, Irving $M$ Retrospective study of 1000 deaths from injury in England and Wales. BMF 1988;296:1305-8.

27 Deane SA, Gaudry PL, Woods P, Cass D, Hollands MJ Cook RJ, Read C. The management of injuries - a reviev

28 Bullock $\mathrm{MRr}$, du Trevou MD, van Dellen JR, Nel JP, McKeown CP. Prevention of death from head injury in Natal 1988;73:523-7.

29 Gordon MWG, Luke C, Robertson CE, Busuttil A. An audit of trauma deaths occurring in the accident and emergency department. Arch Emerg Med 1989;6:10715.

30 Anderson ID, Woodford M, Irving MH. Preventability of death from penetrating injury in England and Wales. Injury 1989;20:69-71.

31 Dykes EH, Spence LJ, Bohn DJ, Wesson DE. Evaluation of pediatric trauma care in Ontario. F Trauma 1989;29:724-9.

32 Kudsk KA, Fardal PM. Preventable trauma deaths. Ohio Med 1988;84:56-61.

33 Crawford R. Trauma audit: experience in north-east Scotland. Br F Surg 1991;78:1362-6.

$34 \mathrm{McNicholl} \mathrm{BP,} \mathrm{Fisher} \mathrm{RB,} \mathrm{Dearden} \mathrm{CH.} \mathrm{Transatlantic} \mathrm{per-}$ spectives of trauma systems. Br $\mathcal{A}$ Surg 1993;80:985-7.

35 Spencer JD, Gopalji B. Audit of 6 months 'activity of a trauma team. Injury 1990;21:68-70.

36 Caldwell MT, McGovern EM. Fatal trauma: a five year review in a Dublin hospital. Ir 7 Med Sci 1993;162:309-12.

37 Thoburn E, et al. System care improves trauma outcome: patient care errors dominate reduced preventable death rate. 7 Emerg Med 1993;11:135-9.

38 Hill DA, West RH, Duflou J. Value of the prospective before and after study as a methodology to evaluate outcome in a trauma centre. Aust N Z F Surg 1993;63:940-5.

39 Hill DA, Lennox AF, Neil MJ, Sheehy JP. Evaluation of Triss as a means of selecting trauma deaths for clinical peer review. Aust N Z F Surg 1992;62:204-8.

40 Wilkinson D. Perinatal mortality - an intervention study. $S$ Afr Med f 1991;79:552-3.

41 Kirkup B, Welch G. Normal but dead: perinatal mortality in non-malformed babies of birthweight $2.5 \mathrm{~kg}$ and over in the northern region in 1983. Br $\mathcal{f}$ Obstet Gynaecol 1990;97:381-92.

42 Birdsall MA, Pattison NS. Lessons to be learnt from a perinatal audit. $N Z$ Med $\mathcal{F}$ 1992;105:54-6.

43 Hazebroek FWJ, Tibboel D, Leendertse-Verloop K, Bos AP, Madern GC, Molenaar JC. Evaluation of mortality in surgical neonates over a 10-year period: non-preventable, permissible and preventable death. F Pediatr Surg 1991; 26:1058-63.

44 Moawad AH, Lee KS, Fischer DE, Ferguson R, Philippe M. A model for the prospective analysis of perinatal deaths in a perinatal network. Am $\mathcal{F}$ Obstet Gynecol 1990;162:15-22.

45 De Muylder X. Perinatal mortality audit in a Zimbabwean district. Pediatric Perinatal Epidemiology 1989;3:284-93.

46 Serenius F, Swailem AR, Edressee AW, Ohlsson A. Cause of perinatal death at a Saudi maternity hospital. Acta Paediatr Scand Suppl 1988;346:70-9.

47 Van Roosmalen J. Perinatal mortality in rural Tanzania. $B r f$ Obstet Gynaecol 1989;96:827-34.

48 Myers SA, Fischer DE, Moawad A, Paton JB, Lee K-S, Ferguson $M$. Assessment of potentially avoidable perinatal mortality in a regionalized program. I Reprod Med

49 Delke I, Hyatt R, Feinkind L, Minkoff $H$. Avoidable cause of perinatal death at or after term pregnancy in an inner-city hospital: medical versus social. Am $\mathcal{f}$ Obstet Gynecol 1988;159:562-6.

50 Andersen KV, Lange AP, Helweg-Larsen K, Andersen E. A perinatal audit of neonatal deaths in three Danish counties. Dan Med Bull 1991;38:382-5.

51 de Caunes F, Alexander GR, Berchel C, Guengant JP, Papiernik E. The Guadeloupean perinatal mortality audit: process, results, and implications. Am 7 Prev Med

52 Eskes M, van Alten D, Treffers PE. The Wormerveer study, perinatal mortality and non-optimal management in practice of independent midwives. Eur 7 Obstet Gynecol Reprod Biol 1993;51:91-5.

53 De Muylder X. Maternal mortality audit in a Zimbabwean province. Arch Gynecol Obstet 1990;247:131-8.

54 Cooreman BF, Cronjé HS, Grobler CJF. Maternal deaths at Pelonomi hospital, Bloemfontein, 1980-5. S Afr Med 7 1989;76:24-6.

55 Jafarey SN, Korejo R. Mothers brought dead: an enquiry into causes of delay. $S_{o c} S_{c i}$ Med 1993;36:371-2.

56 Ashworth MF. Harare hospital maternal mortality report for 1987 and a comparison with previous reports. Cent Afr $\mathscr{f}$ Med 1990;36:209-12.

57 Mertz KJ, Parker AL, Halpin GJ. Pregnancy-related mortality in New Jersey, $1975-89$. Am $\mathcal{F}$ Public Health 1992;82:1085-9.

58 Wittmann BK, Murphy KJ, King JF, Yuen BH, Shaw D, Wittmann AG. Maternal mortality in British Columbia in 1971-86. Can Med Assoc F 1988;139:37-40.

59 Bhatia JC. Levels and causes of maternal mortality in southern India. Stud Fam Plann 1993;24:310-8.

60 Fletcher HJ, Ibrahim SA, Speight N. Survey of asthma deaths in the northern region 1970-85. Arch Disease Child 1990;65:163-7.

61 Robertson CF, Rubinfield AR, Bowes G. Deaths from asthma in Victoria: a 12-month survey. Med $f$ Aus
1990;152:511-7. 
62 Robertson CF, Rubinfeld AR, Bowes G. Pediatric asthma deaths in Victoria: the mild are at risk. Pediatr Pulmonol 1992;13:95-100.

63 Hamblin PS, Topliss DJ, Chosich N, Lording DW, Stockig JR. Deaths associated with diabetic ketoacidosis and hyperosmolar coma, 1973-88. Med $\mathcal{F}$ Aust 1989; 151:439,441-2,444.

64 Will JC, Connell MD. The preventability of premature mortality: an investigation of early diabetes deaths. $A m \mathcal{F}$ mortality: an investigation of
Public Health 1988;78:831-2.

65 Payne JN, Milner PC, Saul C, Bowns IR, Hannay DR Ramsay LE. Local confidential inquiry into avoidable facRamsay LE. Local confidential inquiry into avoidable factors in deaths from

66 Sheldon CA, Churchill BM, McLorie GA, Arbus GS. Evaluation of factors contributing to mortality in pediatric renal transplant recipients. F Pediatr Surg 1992;27:629-33.

67 Stringer MD, Pledger G, Drake DP. Childhood deaths from intussusception in England and Wales 1984-9. BMF 1992 21:737-9.

68 Dubois RW, Brook RH. Preventable deaths: who, how often, and why? Ann Intern Med 1988;109:582-9.

69 McDonald PJ, Royle GT, Taylor I, Karran SJ. Mortality in a university surgical unit: what is an avoidable death? $\mathcal{F} R$ Soc Med 1991;84:213-6.

70 Naraqi S, Gena M. Mortality at the medical wards of a university teaching hospital in Papua New Guinea: a study of 1242 admissions. Papua New Guinea Medical fournal $1989 \cdot 32: 171-6$

71 O'Kelly TJ, Collin J, Murie JA, Morris PJ. Which deaths in vascular surgery are avoidable? A review of 150 consecutive deaths occurring on the Oxford regional vascular service. Eur F Vasc Surg 1990;4:395-9.

72 Hermoni D, Nijim Y, Spenser T. Preventable deaths: 16 year study of consecutive deaths in a village in Israel. $\mathrm{Br} F \mathrm{Gen}$ Pract 1992;42:521-3.

73 Heywood AJ, Wilson IH, Sinclair JR. Perioperative mortality in Zambia. Ann R Coll Surg Engl 1989;71:354-8.

74 Donabedian A. The definition of quality: a conceptual exploration. In: Explorations in quality assessment and monitoring, vol I: the definition of quality and approaches to its toring, vol I: the definition of quality and approaches to its 1980:3-31.

75 Donabedian A. Basic approaches to assessment: structure process, and outcome. In: Explorations in quality assessmen and monitoring, volume I: the definition of quality and approaches to its assessment. Ann Arbor, MI: Health Administration Press 1980:79-128.

76 Donabedian A. Criteria and standards for quality assessment and monitoring $O R B$ Qual Rev Bull 1986;12:99-108.

77 Donabedian A. Advantages and limitations of explicit criteria for assessing the quality of health care. Milbank Memorial Fund Ouarterly 1981;59:99-106.

78 Crombie IK, Davies HTO, Abraham SCS, Florey V. The audit handbook. Improving health care through clinical audit. West Sussex: John Wiley, 1993.

79 Kirkup W. Perinatal audit: does confidential enquiry have place? Br f Obstet Gynaecol 1990;97:371-3.

80 Shaw CD Critet onnaecol 195. BMF 1990;300:649-51.

81 Grimshaw J, Russel I. Achieving health gain through clinical guidelines. Developing scientifically valid guidelines. Quality in Health Care 1993;2:243-8.

82 Bell D, Layton AJ, Gabbay J. Use of guideline based questionnaire to audit hospital care of acute asthma. $B M \mathcal{J}$ 1991;302:1440-3

83 Barendregt WB, deBoer HHM, Kubat K. The results of autopsy of patients with surgical diseases of the digestive tract. Surg Gynecol Obstet 1992;175:227-32.

84 Mosquera DA, Goldman MD. Surgical audit without autopsy: tales of the unexpected. Ann $R$ Coll Surg Engl autopsy: tales

85 Harris MD, Blundell JW. Audit of necropsies in a British district general hospital. $\mathcal{f}$ Clin Pathol 1991;44:862-5.

86 Barendregt WB. Quality control in fatally injured patients: the value of the necropsy. Eur $\mathcal{F}$ Surg 1993;159:9-13.

87 Westerling R. Indicators of avoidable mortality in health administrative areas in Sweden 1974-85. Scand $\mathcal{F}$ Soc Med 1993;21:176-87.

88 Bailar JC, Smith EM. Progress against cancer? N Engl f Med 1986;8:1226-32.

89 Walker A, Petruckevitch A, Bourne H, Burney P. Contributions of incidence and case fatality to mortality from bladThames Regions. I Epidemiol Community Health 1992;46:387-9.

90 Westerling $R$. Components of small-area-variation in death rates - a method applied to data from Sweden. 7 Epidemiol Community Health 1995;49:214-21.

91 Pledger HG, Fahy LT, van Mourik GA, Bush GH. Deaths in children with a diagnosis of acute appendicitis in England and Wales 1980-4. BMF 1987;295:1233-5. 